\title{
RADICALIZACIÓN OBRERA A FINES DE LOS AÑOS '60 EN ARGENTINA: APROXIMACIONES DESDE UNA HISTORIA COMPARADA
}

\author{
WORKER RADICALIZATION IN LATE '60S IN ARGENTINA: \\ A COMPARATIVE APPROACH
}

Marcelo Raimundo*

Resumen: La historia de las protestas obreras en Argentina durante los años ' 60 y principios de los ' 70 ha alcanzado su expresión arquetípica en las experiencias de los obreros clasistas de las fábricas automotrices de la ciudad de Córdoba, una de las ciudades industriales más importantes del país. Estos trabajadores lograron un gran protagonismo durante aquella época por su activo cuestionamiento a los gobiernos dictatoriales y a las patronales extranjeras, como así también, por su capacidad de movilización callejera, por el poder logrado en las plantas pregonando la democracia sindical y por ser los representantes un profundo proceso de radicalización política e ideológica dentro del movimiento obrero de la época. Sin embargo, dentro la historiografía argentina reciente ha quedado planteado un debate sobre el peso y alcance real de este fenómeno en relación al conjunto de las luchas laborales de la época. Por ello, recurrir al estudio comparativo de la realidad obrera cordobesa frente a situaciones presentes en otros lugares del país -en este caso las prácticas sindicales de la región del Gran La Plata- puede ser de utilidad para avanzar hacia un conocimiento más preciso sobre el proceso de lucha de clases que caracterizó a la Argentina y también al mundo por aquellos años

Palabras-clave: Obreros. Clasismo. Córdoba. Gran La Plata. Historia comparada.

\footnotetext{
* Facultad de Humanidades y Ciencias de la Educación - CISH/UNLP - Argentina. E-mail: mraimund@fahce.unlp.edu.ar
} 


\begin{abstract}
The history of labor protests in Argentina during the ' 60 s and early '70s has reached its archetypal expression in the experiences of the clasistas workers of the car factories in Córdoba city, one of the most important industrial cities of the country. These workers achieved great prominence during that time for his active questioning of dictatorial governments and foreign employers, as well as for street mobilization capacity, for workers power at the plants based on the defense of union democracy and for being the representatives a deep process of radicalization political and ideological within the labor movement at that time. However, in the recent Argentina historiography it has been raised a debate about weight and real extent of this phenomenon in relation to all the labor struggles of the time. Therefore, resorting to the comparative study of the working face reality Cordoba events in other parts of the country, in this case the trade union practices of the Gran La Plata can be helpful to move towards a more precise knowledge about the process class struggle that characterized Argentina and the world in those years.
\end{abstract}

Keywords: Workers. Clasismo. Córdoba. Gran La Plata. Comparative history.

ECONOMÍA Y POLÍTICA ARGENTINA DESDE MEDIADOS DE LOS AÑNOS 50

Cualquier referencia a los años ' 60 o principios de los ' 70 en Argentina debe situarse dentro del proceso que se inicia en el año 1955, coincidente con el derrocamiento del segundo gobierno peronista. A partir de entonces comienzan a desatarse abiertamente varios cambios a nivel económico y político que serán la base de un intenso conflicto social que atravesó las dos décadas siguientes. Entre ellos se pueden destacar: 1) inestabilidad de todo intento de estructuración de una nueva alianza dominante a nivel estatal -sin participación obrera/popular- que perpetuará el choque entre distintas fracciones de la gran burguesía por lograr una posición hegemónica en la economía nacional; 2) la profundización del proceso de concentración económica, asociado en gran parte al capital extranjero, que irá avanzando sobre los despojos de la pequeña y mediana burguesía nacional, otrora favorecida por el peronismo; 3 ) una ofensiva empresarial y estatal que desata una racionalización de la estructura productiva privada y pública, un sostenido ataque a los salarios reales, una tendencia a la desocupación industrial y una dualización del mercado de trabajo, factores todos que exacerbarán el conflicto laboral. ${ }^{1}$

La raíz de la inestabilidad política y social y que impidió un arreglo de dominación estable ha sido explicada de distintas maneras según sea el enfoque adoptado: como crisis del sistema político en tanto sistema de partidos; como crisis de la dominación estatal, es decir, como incapacidad del estado para 
dirigir la sociedad; o como crisis de hegemonía, que se traduce en crisis de autoridad de las clases dominantes. ${ }^{2}$ Todas estas caracterizaciones comparten un elemento que surge como condición política fundamental del período y que obstaculiza aún más la posibilidad de resolución de la inestabilidad reinante: la misma proscripción política del peronismo y su expresión a través del sindicalismo peronista. También se coincide en el cambio de etapa que significa el golpe militar de 1966: allí da inicio a una crisis en la ideología reformista obrera (peronista) y en su influencia sobre las bases trabajadores y a un fracasado ensayo de construcción de hegemonía a partir de un estado no permeable a demandas sociales. ${ }^{3} \mathrm{Si}$ estas serían las condiciones en que se desata uno de los períodos de mayor conflictividad social y política de la historia reciente, cabe advertir sobre cierto politicismo analítico que las mismas implican, por lo que es necesario tener en cuenta otras dimensiones que pongan en juego los movimientos desde las clases subalternas: aquí se pueden establecer al menos dos miradas que ponen énfasis en los procesos de luchas sociales y que incorporan elementos para explicar un grado de enfrentamiento social que provocó incluso el ascenso de la violencia armada. Por un lado, para Bonavena, Maañon, Morelli, Nievas, Paiva y Pascual, la razón está en que 1955 se abre una larga etapa en el país que será escenario donde se constituirán dos grandes fuerzas sociales, la de la revolución y la de la contrarrevolución, que adoptarán distintas estrategias objetivas con un claro contenido clasista, más allá de identificaciones políticas o ideológicas. Luego de unos años, con el golpe de 1966, el enfrentamiento tomará una magnitud tal que desencadenará, en términos de estos autores, un proceso de 'guerra civil' que llegará hasta mitad de la década de 1970. ${ }^{4}$ Este proceso tiene un primer subperíodo (1966-1969), que es caracterizado como la formación y maduración de la fuerza revolucionaria, pero como producto de la iniciativa tomada por las fuerzas del orden. A partir de 1969, con el pasaje a la lucha de calles (masas) y el accionar de los destacamentos armados de la fuerza revolucionaria, la confrontación llegará a una escala abierta de guerra civil.

Desde otra línea de análisis - relacionada con la teoría de la acción colectiva- Brennan y Gordillo dan cuenta de la etapa 1955-1973 como 'ciclo de protesta'. ${ }^{5}$ A partir de introducir los 'marcos culturales' y la 'estructura de movilización de recursos', estos autores señalan el cambio que se produce dentro del ciclo de luchas, cuando en 1969 se pasa de una cultura política de resistencia a una de confrontación, conducida por una lógica de eliminación del adversario. Esta misma transformación provocó la aparición de nuevos recursos y repertorios de lucha, expresados tanto por obreros y estudiantes como por las organizaciones armadas, surgiendo así un movimiento social de protesta. Sin embargo, para 1971 se produciría un 'pasaje a la acción política' que hará declinar paulatinamente la protesta social y subsumir la actividad desplegada por los sujetos que la protagonizaban a una nueva lógica, vinculada 
a la apertura política implementada por la dictadura en retirada.

\section{LA CLASE OBRERA EN LOS '60: UNA CONTINUA RECONFIGURACIÓN SINDICAL}

La década de los ' 60 , según la tesis ampliamente aceptada de James, comenzó atravesada por dilemas que surgieron en las dirigencias sindicales nacionales, luego de una serie de derrotas de grandes conflictos obreros originados en las nuevas políticas desplegadas por el gobierno desarrollista de Frondizi ${ }^{6}$. A partir de estos sucesos, cobró fuerza una tensión que se había mantenido contenida durante los años de la llamada Resistencia. ${ }^{7}$ Lucha obrera e intransigencia política, términos que se habían conjugado con bastante armonía en los años previos, comenzaron a cobrar otra significación en un marco donde el gobierno procurando controlar la protesta laboral, ofrecía por un lado represión a la conflictividad -vía el Plan CONINTES-, y por el otro el premio de la legalidad-reconocimiento oficial a la dirigencia sindical y promesa de normalizar la Confederación Nacional del Trabajo (CGT) nacional. ${ }^{8}$ De esta manera, se impuso la idea que continuar con la lucha sindical directa y abierta contribuía al deterioro y regresión de la organización obrera. Así, el pragmatismo institucional reinó durante gran parte de la década como política sindical hegemónica, legitimándose en la desmovilización de gran parte de las bases y activismo sindical. ${ }^{9}$ En este marco, la existencia y funcionamiento de un sistema de negociación colectiva dominado por las organizaciones de nivel nacional permitía gran efectividad, haciendo perder sentido a cualquier iniciativa de activistas y de las instancias organizativas de las bases trabajadoras. ${ }^{10}$

A partir de 1966 esta situación comenzó a resquebrajarse, ya que la política estatal de la nueva dictadura no dejaría lugar a la mecánica que sustentaba el poder sindical: la presión desestabilizadora a través de grandes huelgas para luego llegar a acuerdo entre estado, empresarios y cúpulas sindicales. Así, el desmantelamiento del sistema de negociación centralizado como organismo mediador provocó divisiones y nuevos alineamientos a nivel de las direcciones sindicales, como también el florecimiento formas organizativas más cercanas a las bases, que recordaría a la etapa de la Resistencia, pero esta vez de la mano de los trabajadores de la nuevas industrias dinámicas, arrasando con buena parte de la legitimidad gozada hasta el momento por los líderes sindicales. La ruptura de la pasividad y la rebelión de las bases, que en algunos casos se expresaron en un cambio de las direcciones gremiales y una radicalización práctica e ideológica, marcaron el lapso que va desde el Cordobazo hasta la primera etapa del tercer gobierno peronista. ${ }^{11}$ Sin embargo, la represión estatal desatada y la fidelidad ideológica de las bases al peronismo implicaron el agotamiento de las expresiones más 
avanzadas, que vivieron un breve resurgir recién hacia mediados de 1975 para luego ser aplastadas por una nueva y feroz dictadura.

Es en este contexto histórico y con epicentro en Córdoba donde se ubica la emergencia del clasismo como nueva fuerza sindical, y que por sus mismas características fueron obligando a ampliar las variables de análisis utilizadas para comprender su naturaleza. ${ }^{12}$ Brennan es uno de los que ha logrado poner en juego diversas variables que James no contempla en profundidad y que resultan claves para comprender este nuevo fenómeno obrero: el lugar de trabajo, la cultura política y los estilos sindicales. ${ }^{13} \mathrm{Cada}$ una de éstas, a su manera, funcionó como condicionante para la emergencia del sindicalismo clasista: 1) las características de la organización de la producción y de los procesos de trabajo en una etapa de racionalización de la industria dieron las condiciones materiales para dicho surgimiento; 2) la cultura política de izquierda, muy presente en la atmósfera cordobesa, otorgó la posibilidad de una alternativa a la hegemonía del gremialismo peronista; 3) la clara identidad regional de los sindicatos frente a las intromisiones porteñas, que dio sostén a un pluralismo gremial y a renovadas alianzas, hizo viable una conciliación entre la pertenencia ideológica peronista de las bases y una dirigencia sindical no peronista, cuando este estilo de conducción no dio respuestas a la racionalización.

En verdad, el aporte de este autor no se redujo sólo a una profundización del caso, sino también contuvo consecuencias interpretativas más generales sobre la caracterización y dinámica del período entero. Hay que tener en cuenta que este autor hace su análisis ubicando al caso argentino dentro de un conjunto de experiencias con algunos casos similares y contemporáneos: las protestas y combatividad expresada por los sindicatos de trabajadores mecánicos en grandes plantas automotrices en México y Brasil. ${ }^{14} \mathrm{Su}$ tesis central es que hay una especificidad en el caso cordobés, ya que comparado con los otros, este produjo un diferencial: dio por origen a una radicalización política e ideológica con claros componentes anticapitalistas: "A primera vista, la prolongada historia de militancia e incluso de radicalización política de los sindicatos cordobeses podría parecer sugerir que su experiencia fue excepcional". ${ }^{15}$ Este carácter de 'excepcionalidad' puso en cuestión el lugar del clasismo como parte de una evolución de las luchas de la clase obrera en el país, ya que lo que se procuraba era despegar al clasismo de un reduccionismo politicista y ubicarlo dentro de una constelación singular que suman elementos económicos y culturales. Contra esta posición Iñigo Carrera, señala que el problema fundamental es entender el fenómeno obrero cordobés dentro de la dinámica de los procesos históricos de clase, y por eso propone como ejes de ponderación, cómo se articula la clase trabajadora, en qué momento de su historia está y cuál es la tendencia de la lucha de clases. ${ }^{16}$ Con esta base, critica el carácter extraordinario y ubica a Córdoba como parte 
de una tendencia general. Sin embargo, esto no era negado por Brennan, quien autovaloraba su estudio porque:

tiene utilidad no sólo para entender la historia de la Argentina en las décadas de 1960 y 1970, sino también para una mejor comprensión de la relación del movimiento obrero organizado y la política en la historia moderna de América Latina y para rastrear las fuentes de la política obrera en general ${ }^{17}$

Posteriormente, Iñigo Carrera acercaría posiciones reconociendo que lo excepcional de Córdoba fue ser el 'eslabón débil' de la situación nacional, y por ello pasaría a tener una relevancia única por tener justamente ese papel. ${ }^{18}$ En resumen, el caso cordobés entonces, funciona en la discusión a modo de un particular que habla de la situación nacional, asimilada a una tendencia general. La diferencia radica en las apreciaciones sobre qué papel juega esta última, yendo los autores en sentido opuesto: Córdoba como singular expresión de la tendencia versus Córdoba como excepción que confirma la regla. Habría que tener en cuenta también, que en última instancia como afirma Pablo Pozzi, la existencia o no de excepcionalidades es un problema de comparación histórica. ${ }^{19}$ Por eso, debates como el planteado, se complejizan aún, si ponemos otra escala de análisis, como puede ser la mundial: Beverly Silver ha demostrado en su estudio de conflictividad laboral a escala mundial patrones similares al de Córdoba en otras regiones del planeta, asociados a casos de combatividad de los obreros mecánicos y varios acompañados de procesos de radicalización política. ${ }^{20}$

Quizás para salir de este tipo de atolladero histórico, uno de los caminos que están a mano es realizar un desplazamiento en los significantes y para la búsqueda de singularidades ligadas a definir especificidades locales o regionales, realizar comparaciones enfocando 'lo excepcional' del caso, más que 'el caso' excepcional. De esta manera, el modo, la forma en que se dan los conflictos obreros locales y las dinámicas sindicales puede ser un enfoque adecuado para observar tanto de la presencia de patrones considerados generales, como de lo singular o lo excepcional. Con esta mira, nos acercaremos a aspectos de la historia de la clase obrera platense de los años ' 60 .

\section{POLÍTICA Y PARTICIPACIÓN EN LOS SINDICATOS PLATENSES}

La pequeña región que en un radio de aproximadamente 15 kilómetros comprende a las ciudades de La Plata, Berisso y Ensenada, se denomina actualmente "Gran La Plata" conformaba en los años '60 el cuarto conglomerado poblacional e industrial del país y es la zona que será objeto 
del análisis comparativo propuesto. Berisso, era un calidoscopio étnico hecho comunidad obrera por una otrora floreciente industria frigorífica, pero que comienza a despedazarse por esos años. Ensenada, se convirtió en esos años sede de un polo petrolero-petroquímico ejemplo de las nuevas industrias dinámicas y que se sumó a uno de los astilleros más importantes del país. La Plata, una ciudad universitaria y comercial, que además contaba con la presencia de algunos grandes centros laborales industriales y de servicios, como de importantes talleres ferroviarios. Esto fue acompañado de una dimensión que agregó complejidad a la zona: su condición de sede tanto de la administración estatal como de federaciones sindicales de la provincia de Buenos Aires, sumando así un plus de conflictividad proveniente de la escala regional y del sector de los trabajadores públicos provinciales.

A tono con la realidad obrera nacional, la mayoría de los sindicatos platenses eran conducidos por peronistas, aunque divididos en grupos por sus diferencias internas en relación a la política sindical nacional. El liderazgo peronista, si bien encontraba su raigambre en la adhesión ideológica de las bases trabajadoras al este movimiento político, se sostuvo también por control férreo del aparato sindical y la coerción ejercida hacia las oposiciones gremiales en sindicatos y lugares de trabajo. ${ }^{21}$

Distintas fuentes, informan como los militantes que buscaban organizar trabajadores por fuera de estas conducciones en la región se encontraban con diversos problemas, sobre todo en los grandes sindicatos. Un grupo de activistas políticos de la época opinaba sobre el gremio de la construcción: "Terribles policías denuncian activistas en las obras y tienen 'delegados' ya hechos a quienes meten a trabajar en las obras p/organizar [sic]". ${ }^{22}$ En el Astillero Rio Santiago, la delación a la patronal era aún más grave, porque el gerente general de esa empresa estatal por entonces era un alto oficial de la Marina: "Equipo de matones que en asambleas se hacen sentir como así también en volanteadas hechas en puerta de fábrica en que han botoneado gente" [sic]. ${ }^{23}$ Había casos en que las patronales ofrecían información, e incluso logística, para la persecución policial de activistas sindicales. Un jefe de seguridad de una gran fábrica ofreció incluso incorporar a policías con puestos remunerados, según relataba a sus superiores un oficial de inteligencia:

En la Empresa no existen problemas de tipo laboral y los salarios están ajustados de acuerdo al último convenio colectivo celebrado entre las partes y considera que se debe tratar de un pequeño grupo que quiere crear un clima de intranquilidad en la Petroquímica y que se dedican a molestar en los micros que transportan al personal y que deben pertenecer a una pequeña célula de orientación izquierdista que ellos no se encuentran en condiciones de 
detectar, dado que el personal de vigilancia se encuentra afectado casi exclusivamente a tareas administrativas, control de vehículos, etc. ${ }^{24}$

Cabe señalar, que la tendencia general al aumento de los mecanismos burocráticos en los sindicatos, se daba en el marco de una continuidad ininterrumpida de elecciones sindicales cada 2 años, incluso durante los años dictatoriales, salvo en algunos sindicatos intervenidos por el gobierno como represalia a huelgas. Esta cuestión deja vislumbrar que la hegemonía sindical se apoyaba en cierta legitimidad hacia los dirigentes sindicales más allá de los mecanismos de control.

\section{¿ACTIVISTAS Y AGITADORES?}

Hacia comienzos de 1968, y luego del congreso normalizador "Amado Olmos" que dio origen a la CGT de los Argentinos, aumentó la preocupación de las fuerzas represivas por la movilización sindical que esto podría provocar. ${ }^{25} \mathrm{Si}$ bien la conflictividad era casi insignificante desde hacía un año producto del acrecentamiento de la represión dictatorial, la policía bonaerense solicitó inmediatamente un panorama de la situación sindical a su departamento de inteligencia. ${ }^{26}$ Este llegó a informar una lista de veintiocho militantes sindicales, varios de ellos considerados agitadores 'activos' -y con cierto grado de peligrosidad- y casi la mitad de ellos con prontuarios previos. Según los datos domiciliarios, los activistas radicados en La Plata y Berisso estaban en número parejo y eran casi el $80 \%$ del total. El mayor número de militantes identificados pertenecía a la destilería de YPF; llamativamente le seguían en orden varios trabajadores de la industria del vidrio -industria menor en la zona-, todos de 'orientación comunista', y luego los de frigoríficos y astilleros, estando el resto distribuidos en 14 lugares de trabajo o gremios distintos. De acuerdo a la clasificación policial, la mayoría de los identificados -casi el 60\%- eran comunistas, el $25 \%$ peronistas y el resto eran considerados izquierdistas y trotskistas. En realidad estos números estarían mostrando, más que una representación del peso real de estas corrientes en el movimiento obrero local, cierto retraso en la adecuación del espionaje policial a los nuevos cánones y desafíos represivos inaugurados por la Doctrina de Seguridad Nacional, impulsada en toda Latinoamérica a mediados de la década de los '60 por los Estados Unidos, en el marco de la 'guerra fría”. Así, una militancia sindical de base que se fortalecía lentamente hacia esos años aún no estaba en el centro de la observación, y todavía conservaban la prioridad los 'elementos comunistas'.

Estos, solían estar asociados al Movimiento de Unidad y Coordinación Sindical (MUCS), corriente que, según la policía, estaba bastante debilitada hacia fines de 1966 y "sin gravitación alguna dentro del panorama gremial local". ${ }^{27}$ De hecho, los referentes de este nucleamiento eran todos ex- 
dirigentes de los sindicatos platenses de la industria del vidrio, del papel y de los pintores, que habían sido desplazados de los mismos por su condición ideológica pero se mantenían activos públicamente: “A pesar de hallarse alejados de sus agremiaciones (...) se autotitulan dirigentes del M.U.C.S. y en su representación, confeccionan y dan a publicidad comunicados en la prensa local", como bien se puede observar a lo largo de las noticias gremiales de esos años, sobre todo en el marco de huelgas y protestas estudiantiles. ${ }^{28} \mathrm{Si}$ bien, como se indicaba, estos datos mostraban su debilidad, es cierto también que la inteligencia policial tenía problemas para ponderar con exactitud la penetración del comunismo en los sindicatos en virtud de la práctica de sus militantes:

Cuando creen que de concurrir a los comicios les puede deparar un fracaso, tratan de infiltrar sus elementos en las listas de mayor ascendencia [...] Es bien sabido que la táctica de infiltración persigue como finalidad, el ubicar a sus elementos de la mejor manera posible en la fracción que mejor se preste al logro de sus objetivos. Resulta un tanto difícil establecer si existen retraimientos por parte de los comunistas hacia el M.U.C.S. ya que en los sindicatos donde existe infiltración en la C.D., éstos no cuentan con la fuerza suficiente para arrastrar al resto de los dirigentes hacia esa fracción. ${ }^{29}$

Más allá de esta forma de accionar, es verdad también que tenían una fuerte militancia de base histórica en los frigoríficos de Berisso, en donde además hubo mucha actividad sindical en los ' 60 a raíz de la permanente racionalización e inestabilidad laboral a la que estuvieron sometidos sus trabajadores. ${ }^{30}$ Así lo demuestran las elecciones del sindicato de la empresa Armour de enero de 1961, donde la lista Celeste (comunista) obtuvo el segundo puesto con 1.074 votos, muy cerca de los 1.270 sufragios obtenidos por la oficialista y peronista lista Azul. A la hora de explicar estos resultados, la inteligencia policial señalaba a sus superiores:

La cantidad de sufragios obtenidos se debe exclusivamente a la gran campaña realizada, desde tiempo antes de la elección, en que células comunistas de la zona y de la Ciudad de La Plata, se encargaron de visitar a gran cantidad de afiliados en sus domicilios, exponiéndoles las ventajas y razones que recibirían los trabajadores con el triunfo de la misma. Solamente se consiguió la derrota de esta lista 24 horas antes de las elecciones, en que dirigentes de la Lista Azul se movilizaron rápidamente por Secciones 
del Establecimiento Frigorífico [sic], en los medios de transporte y en la población en general, haciéndoles notar a los votantes el neto corte comunista de la Lista Celeste y las consecuencias que traerían aparejadas al sindicato el triunfo de la misma. ${ }^{31}$

En el Frigorífico Swift, a fines de 1960 la comunista lista Marrón apoyó a la lista Rosa de Héctor Guana, que logró así derrotar a la peronista Verde y Blanca en las elecciones del sindicato. En cambio, para la votación de mayo de 1963, los comunistas fueron por separado en la lista Celeste y obtuvieron 731 adhesiones -un 14\% del total de votos-, lo que provocó una merma de votos para la Rosa y permitió retomar la conducción a los peronistas anteriormente desplazados. En 1965, ya con los sindicatos unificados, vuelven a forman parte de la lista Rosa Unidad y triunfan, para luego separarse nuevamente en las elecciones de 1967. Se puede comprobar la presencia, aunque menguante, de esta corriente al menos hasta 1971, cuando el personal de inteligencia le dedica un extenso informe a la actuación de una célula en el que se develan formas de operatoria para repartir propaganda, la existencia de un supuesto mecanismo de favores laborales y ascensos entre activistas y colaboradores, y la articulación entre militantes de las distintas localidades. ${ }^{32}$ Cabe destacar que, aunque la actividad sindical comunista fue generalmente camuflada, en los momentos en que el régimen político lo permitía las tareas partidarias se desarrollaban abiertamente.

\section{LAS BASES PARA UNA NUEVA MILITANCIA FABRIL}

Como se señaló arriba, todavía a fines de los años 60 los legajos sindicales policiales ponían uno de sus principales focos en la militancia comunista, y de manera más rutinaria y menos profunda sobre algunos dirigentes del peronismo, pese a que el movimiento obrero local adscribía mayormente a esta ideología. En realidad, ambas corrientes militantes, que daban vida al sindicalismo platense -y argentino-, eran parte de lo que podría llamarse una vieja camada sindical, que le dio el tono a las luchas obreras locales de fines de los '50 y de gran parte de los '60. Pero llegados los años '70, el lugar predominante del peronismo en el sindicalismo local, y el de los comunistas como la izquierda sindical, deberán dar paso a una nueva camada militante, una nueva generación de activistas que lentamente se fueron afianzando en el período y pusieron en cuestión el campo sindical dominante.

Esta nueva camada, asociada a un renovado activismo de izquierda, se encontró en gran medida más cercana a los trotskistas locales (mas no se redujo a ellos) que a los comunistas. Durante gran parte de la década del ' 60 , si bien el comunismo platense poseía militancia en varios sindicatos, a la vez mostraba 
una clara tendencia declinante en su ascendiente sobre las bases, aunque con excepción de algunos cuadros que poseían cierto predicamento pero estaban aislados organizativamente. En cambio, en esos años se sostuvo un lento pero permanente trabajo sindical de trotskistas en los frigoríficos de Berisso. Fue Castillo quien abordó por primera vez la experiencia de la agrupación El Activista de la Carne y su expresión electoral la Lista Gris, enfocando sus propuestas y prácticas sindicales entre los años 1967 y 1972 como expresión del Partido Revolucionario de los Trabajadores - La Verdad (PRT-LV) y por lo tanto de la corriente política conocida como morenismo. ${ }^{33}$ Según este autor, la actuación del El Activista de la Carne se remonta a 1965, cuando apoyó a la Lista Rosa de Unidad que resultó triunfante contra los antiguos dirigentes peronistas. Al poco tiempo se convirtió en una tenaz oposición hasta el final de su historia, apelando a la denuncia y a la lucha por los distintos problemas que atravesaban los obreros de la carne: suspensiones, despidos, bajos salarios, racionalización productiva, condiciones de trabajo. Sin embargo, la actuación de los morenistas en Berisso ya había sido registrada unos años antes, en 1960, cuando la policía logró disolver a unas 70 personas que intentaban llevar a cabo una asamblea popular contra los despidos provocados por la huelga, advertida por el hallazgo de un volante firmado por Palabra Obrera, que como parte de la Comisión Coordinadora del Armour la convocaba.$^{34}$ Durante estos años, al parecer, las apariciones de los morenistas fueron más públicas que sindicales. Otro caso informado detalladamente fue una mesa redonda en septiembre de 1962, organizada por la comisión de solidaridad del Armour y por un conocido cura obrero de la zona: allí, un participante que se identificó de Palabra Obrera intentó arrancar a los convocantes del evento el llamado a una 'marcha del hambre', pero la cuestión, como otras tantas iniciativas planteadas por varios comunistas presentes, fue rápidamente repelida por el sacerdote. ${ }^{35}$ Además de los morenistas, se puede registrar paralelamente la existencia en la misma localidad de otra corriente trotskista: el Partido Obrero Revolucionario (POR)

En términos estrictamente sindicales, recién hacia el año 1963 se puede empezar a encontrar algunos rastros escritos de la actividad trotskista, a través de volantes que referían a las elecciones nacionales de la Federación de la Carne. En ellos, tanto la Lista Granate como El Activista de la Carne apoyaban a la Lista Verde contra las comandadas por los dirigentes Cardoso y Escalada, priorizando la lucha contra quienes se consideraban entregadores de la huelga de 1962 y del convenio colectivo de 1946:

Sabemos que no hay ninguna lista ideal, pero sí creemos que la derrota de las Direcciones tradicionales posibilita la organización del gremio y en esa medida enfrentar a la patronal. Hoy tenemos una oportunidad más de lograrlo; hay una lista que tiene un programa para frenar a la Patronal; 
por ejemplo en su programa figura la reorganización de las comisiones internas y los cuerpos de delegados, que son los cimientos indispensables para convertir de vuelta a nuestro Sindicato en baluarte antipatronal $[\mathrm{sic}] .{ }^{36}$

Así, queda planteado tempranamente uno de los ejes que estas corrientes intentarán poner en práctica de aquí en adelante: impulsar la organización en el lugar de trabajo, cuestión que va a estar estrechamente vinculada en los frigoríficos no sólo a los reclamos salariales y de estabilidad laboral, sino también a la lucha contra el deterioro de las condiciones de trabajo en un marco de racionalización capitalista. De allí que la solución a todo problema presente en la fábrica suela ser planteada por el lado del fortalecimiento de la participación y de la organización de las secciones y cuerpos de delegados. ${ }^{37}$ Desde fines de los años 60, los boletines de El Activista de la Carne sostuvieron continuamente entre sus primeras consignas la exigencia de 'normas humanas de trabajo'. He aquí con una importante coincidencia con lo motorizado por las distintas experiencias clasistas cordobesas.

La ocasión que daban las elecciones sindicales se ajustaba perfectamente al intento de estos militantes de organizar a los trabajadores, por eso los trotskistas nunca desdeñaron su participación en las contiendas sindicales, pues para fortalecer la base obrera se necesitaba además una 'nueva dirección', aunque marcaron sus diferencias. Tómense como ejemplo estas expresiones de la agrupación Lista Granate ante las elecciones de 1965, cuando las mismas no eran vistas sólo como un modo de ganar el sindicato: "Por eso esta lucha electoral debe ser usada para imponer delegados. Llamamos al gremio a no esperar de las elecciones para imponer sus delegados en las secciones, nombrando los más combativos, sacando a los flojos". ${ }^{38}$ Mientras tanto, El Activista de la Carne daba su apoyo a la lista Rosa de Unidad, otorgando prioridad a las prácticas antidemocráticas del oficialismo en el gremio de la carne. Distintas apuestas manifestaban las diferencias entre las corrientes, y a la larga también la idea de 'frente único' dejó de estar presente en las consignas electorales, o, si lo estuvo, fracasó.

\section{UNA NUEVA CAMADA MILITANTE}

Si Berisso había sido cuna y baluarte en la afianzamiento de una nueva corriente de izquierda sindical, no alcanzó en aquella localidad un despliegue mucho mayor del que ya tenía el comunismo en los frigoríficos, más allá de sus intentos de diferenciarse de éste tanto en las formas de militancia y propaganda como en el énfasis puesto en condiciones de trabajo y el poder obrero en la sección. Hay que recordar, que el clasismo cordobés dio en el clavo justamente por dar respuestas a demandas de este tenor; pero a diferencia de las automotrices, los frigoríficos berissenses estaban en pleno declive y 
cerrarían sus puertas unos años después, para dejar a miles de obreros y sus familias en la calle.

Lo que se puede considerar una nueva camada de activismo sindical, ligada más estrechamente al proceso de radicalización obrera que crecía en el país, surgirá en una de las 'industrias de punta' de la región recién hacia fines de la década de 1960, en la fábrica de fibras sintéticas Petroquímica Sudamericana ubicada en la periferia de La Plata. Aunque es un caso singular en la zona, la conflictividad en esta empresa se desarrolló con bastante "simultaneidad" a ciertos ciclos de las luchas obreras cordobesas y sus expresiones, aunque también conserva sus distancias. Según un estudio sobre las experiencias de organización y luchas sindicales en este establecimiento, se confirma que sin dudas:

La militancia de izquierda en Petroquímica fue notoriamente intensiva en el período abarcado (19691973). Se ha verificado la existencia de una gran cantidad de agrupaciones políticas con militantes dentro de la fábrica, o ligadas a los trabajadores de la misma. Muchas de ellas conformaron agrupaciones político-sindicales en el interior del establecimiento. ${ }^{39}$

Respecto al largo y combativo conflicto acaecido en la empresa durante 1971, Bretal asegura que "Esta huelga tuvo mucha influencia de la militancia de izquierda regional, que asimismo se encontraba intensamente vinculada a algunos trabajadores de esta fábrica" ${ }^{40}$ En verdad, los datos provistos por la inteligencia policial no dejan dudas de esto, ya que en el expediente de espionaje de la fábrica se pueden encontrar 21 volantes arrojados en distintas instancias entre 1969 y 1971, tanto dentro como en la puerta de la fábrica. Entre ellos estaban los firmados por "Trinchera Textil", "Avanzada socialista" o "Avanzada Petroquímica", y los de la "Comisión de Resistencia Clandestina", todos ellos comprobando la existencia de agrupaciones fabriles. Estás eran parte respectivamente de Política Obrera (PO), del Partido Revolucionario de los Trabajadores La Verdad (PRT La Verdad), y de un grupo ligado al Partido Comunista Marxista-Leninista argentino (PCML). También se encontró propaganda del Partido Comunista Revolucionario (PCR) y de grupos sin filiación reconocida como "Agrupación Lucha Obrera Petroquímica" y "Obreros y Clasistas Revolucionarios".

La militancia sindical allí comenzó tempranamente, pues la empresa se instala en 1959 y ya para 1963 se pueden encontrar rastros de los primeros intentos de organización sindical, motorizados por activistas de la Asociación Obrera Textil (AOT). Durante el año 1964, los obreros de la empresa participaron activamente de una gran toma de fábricas en el marco del Plan de Lucha de la CGT, mostrando un activo compromiso con 
la medida. Se sigue confirmando un par de años después -hacia mediados de 1965- que sectores de izquierda buscaban fortalecer su presencia en la fábrica, en el marco de un conflicto planteado durante meses en donde la empresa se negaba a discutir el convenio laboral. En la ocasión y al final de una reunión con 300 trabajadores de Petroquímica, un grupo de militantes del Partido Revolucionario de los Trabajadores (PRT) realizó una actividad propagandística -a través de la cual se puede confirmar su conocimiento en detalle del conflicto- donde llamaban a fortalecer la comisión interna con los obreros más comprometidos y proponían la "edición de un boletín interno que sea el verdadero centro de información y opinión de todos los compañeros de la fábrica, que rompa toda campaña de falsos rumores, arma fundamental de la patronal". ${ }^{41}$ Dicho problema se arrastró hasta las fiestas de fines del '65 y terminó desencadenando una violenta ocupación de la fábrica con decenas de rehenes, suceso que estremeció a la región. En esa ocasión circuló un boletín titulado Quién es Petroquímica Sudamericana de una "Comisión de Prensa y Propaganda", cuya redacción -además de incluir vagamente algún léxico propio de la izquierda- registra aspectos que serán materia de permanentes conflictos en la relación entre los patrones y obreros en esa fábrica: la dilación empresaria con las negociaciones y el despido sistemático de activistas sindicales, sobre todo de las comisiones internas, durante y después de los conflictos. ${ }^{42}$ Recién hacia 1967 la comisión interna fabril es reorganizada, y queda comandada por la única lista que se presentó a elecciones, la Verde, una continuidad de la anterior y vinculada la dirigencia peronista de la AOT berissense, logrando 290 votos.

Posteriormente, al ser intervenido el gremio textil platense por orden del sindicato nacional, se produjo un grieta entre parte de los sindicalistas textiles de La Plata y los de Berisso, que la izquierda supo aprovechar muy bien, por lo que a partir de 1969 comenzará nuevamente a crecer el activismo en la fábrica, pero esta vez prácticamente hegemonizado por ella. Desde principios de aquel año la comisión interna se reorganizó, y para marzo lanzó un llamado a asamblea de los cuatro turnos y todas las secciones para enfrentar una racionalización laboral en una sección muy importante de la fábrica, denunciando el incumplimiento del convenio vigente ya que los empleadores no hicieron las comunicaciones previas sobre tareas y salarios. La comisión interna reclamaba a la vez su reconocimiento, citando el convenio laboral: "Los obreros/as por sí o por intermedio de las Comisiones Internas o de Reclamos y/o de los representantes sindicales reconocidos, podrán plantear al empleador todas las objeciones que crean oportunas". ${ }^{43}$ Ello resultaría siempre difícil en Petroquímica Sudamericana por la constante agresividad que sufría cualquier tipo de organización en la fábrica; sin embargo, como se ha visto, la patronal debió enfrentar periódicamente a tenaces activistas dispuestos a la lucha, más allá de las ideologías que portasen. 
Después de meses de infructuosos y crecidos reclamos, la comisión interna lanzó un quite de colaboración por tiempo indeterminado, pidiendo por aumento del $20 \%$, respeto del convenio, mejor atención médica, comedor digno y más baños. También se luchaba por la movilidad de los delegados entre secciones, y en este conflicto quedaba bastante claro cuál era la relación que la comisión interna propiciaba con el cuerpo de delegados: "El Delegado de turno tiene facultades para decidir con su turno las medidas inmediatas a tomar. Estas medidas serán apoyadas por el resto de la Comisión y el conjunto de la Fábrica". ${ }^{44}$ La empresa aprovechó la situación y despidió a 500 obreros acusándolos de adherir al paro decretado por una de las centrales sindicales nacionales el 1 de julio; luego los reincorporó, pero dejó en la calle a nueve integrantes del cuerpo de delegados, vale decir la totalidad de la comisión interna, y participantes de la lista Verde, debilitando aún más al peronismo gremial de Petroquímica Sudamericana. ${ }^{45}$ De allí se inició un interregno de parálisis, que se revirtió recién entrado el siguiente año, ya que al calor de las huelgas generales decretadas por la CGT comenzó la consolidación de una izquierda sindical en la empresa por varios años.

A fines de marzo de 1970, a raíz de un conflicto entre operarios de la sección Poliéster y el supervisor por el cual la empresa despidió a 9 trabajadores del turno noche, volvió a escena la comisión interna -bajo el título de 'reorganizadora'-, emprendiendo la defensa de los cesanteados a través de una denuncia en la Secretaría de Trabajo. Aquella represalia patronal no desanimó a los obreros, que, por el contrario, adhirieron con fuerza al paro general de la CGT del 23 de abril de 1970. Todo esto dio impulso a la comisión interna reorganizadora, que fue al parecer lograda a regañadientes, ya que el delegado reorganizador interventor temporario -que había enviado la AOT nacional a La Plata- había dilatado el trámite al no ver garantizada la continuidad de la predominancia peronista en la fábrica. Con un mandato de sus compañeros por tres meses, un heterogéneo conjunto de activistas rápidamente se volcó a la organización de la fábrica a través de la reconstrucción del cuerpo de delegados, una tarea que encontró varios obstáculos, sobre todo para las comunes aspiraciones de los activistas de izquierda. Si por una parte expresaban que "(s)atisfactoriamente estamos comprobando que los petitorios que circulan están siendo tomados con seriedad por los compañeros y ya hay muchas secciones donde se han elegido delegados", por otra reconocían que aún faltaba mucho que organizar y llamaban a 'tomar conciencia': "Creemos que este es el camino para terminar con el temor que venimos arrastrando de tiempo atrás y conseguir conquistas en Petroquímica. POR LA INMEDIATA ELECCION DE LOS DELEGADOS. FIRMEMOS LOS PETITORIOS MASIVAMENTE. ELIJAMOS A LOS COMPAÑEROS MAS COMBATIVOS" [sic]. ${ }^{46}$ Por aquellos momentos, el intento de organizar la comisión interna chocaba también con la política de dos grupos presentes 
en la fábrica, Trinchera Textil y Comisión de Resistencia Clandestina, que, como el nombre del último indica, bregaban en reiterados volantes por la organización clandestina sindical y criticaban los intentos organizativos de los otros sectores militantes. ${ }^{47}$

Así, señales de una nueva camada de activismo gremial se asoman a través de estos discursos, aunque no sólo por el estilo o algún contenido sino también por el mismo hecho de que tener un nuevo discurso -en este caso clasista- para las bases obreras comienza a ser una de las prácticas en la fábrica. Esta militancia 'izquierdista', según confirmaba el espionaje policial, encontraba su base de apoyo en la dura política de la dirección fabril hacia los trabajadores:

(D)esde tiempo atrás se observa en el sector obrero un clima de malestar motivado por las numerosas sanciones disciplinarias y despidos aplicados por la patronal, generalmente por motivos que normalmente no debían dar causa a tales sanciones. Igualmente, los cambios de sistema de trabajo en algunas secciones -siempre en detreimiento [sic] de los obreros- concurrieron a ahondar las desinteligencias. ${ }^{48}$

El proceso de recomposición sindical en la empresa se consolidó recién hacia septiembre de 1970, cuando finalmente se realizaron las elecciones normalizadoras de la AOT seccional La Plata. En ellas triunfó la lista Marrón sobre la Gris -por 604 votos contra 483-, logrando así establecerse una conducción que, si bien era de origen peronista, anclaba su legitimidad en el apoyo de un sector importante del nuevo activismo de base. Los secretarios elegidos eran gremialistas jóvenes, de 26 y 28 años respectivamente. ${ }^{49} \mathrm{La}$ juventud de los activistas obreros de la fábrica, en consonancia con otra de las tesis sobre el clasismo cordobés puede confirmarse por ejemplo con la lista de detenidos a lo largo de la huelga de 1971, donde la mayoría estaba entre $\operatorname{los} 20$ y 30 años. ${ }^{50}$

La nueva realidad organizativa se hizo sentir rápidamente, cuando se suscitó un importante conflicto por la adhesión del sindicato textil a la huelga general de la CGT del 9 de octubre de 1970. Esa noche, después de finalizada la medida -que en Petroquímica fue de acatamiento total- la empresa sólo dejó ingresar a 25 de 250 trabajadores, declarando que se iban a aplicar suspensiones y cesantías; la cuestión fue respondida de inmediato con paros en todos los turnos por parte de los delegados obreros. En tres días las suspensiones eran cerca de 1.000, por lo que las asambleas excedían la capacidad de la sede gremial y debían ser convocadas en el gran local del sindicato de los trabajadores universitarios ATULP. La disputa fue superada cuando la dirección empresaria accedió a cambiar las suspensiones por 
vacaciones adelantadas, trato ampliamente aprobado por las bases. En rigor de verdad, esa había sido la propuesta original llevada por los trabajadores ante el aviso patronal de una reducción en la producción:

(L)a huelga del viernes fue lo que necesitaban para aplicar las suspensiones. Nosotros habíamos sugerido que se dieran vacaciones al personal, pero no fuimos escuchados. Siempre se ha querido quebrar la unidad obrera en Petroquímica y para ello se ha llegado a despedir delegados y dirigentes que actuaban en la planta. ${ }^{51}$

La empresa estaba decidida remarcar su autoridad en la fábrica. Las tratativas fueron acompañadas por una marcha de 400 obreros que en principio fueron dispersados por la policía, pero de todas maneras permanecieron en grupos por el lugar y muchos lograron acceder al lugar donde se desarrollaba la negociación. Nuevamente algo por el estilo se volvió a suscitar, ante la adhesión al paro general de la CGT de 36 horas del 12 y 13 de noviembre, cuando la empresa tomó represalias dejando a 400 trabajadores suspendidos, por considerar insuficientes la cantidad de obreros que mantuvieron la guardia. Después de algunos días se llegó a un trato: a cambio del levantamiento de las suspensiones se abonaría la mitad de los jornales perdidos y se haría un estudio científico de la cantidad de guardias necesarias durante las huelgas. ${ }^{52}$ En esta ocasión también hubo una movilización por el centro platense de 300 trabajadores, que junto a un número importante de ocasionales transeúntes terminó gaseada por la policía. Hay que recordar, que las demostraciones públicas no eran toleradas en absoluto durante la dictadura reinante por aquellos tiempos, ya que la ocupación de la calle era considerada un desafío directo a la autoridad gubernamental.

Hasta aquí se han expuesto muestras de cómo se fue consolidando en la región platense una experiencia sindical de nuevo cuño, que compartía muchos de los rasgos considerados en la historia obrera argentina como pertenecientes tanto a las prácticas como a los sindicatos clasistas. Entre los más relevantes de estos aspectos, se podrían señalar: 1) el aumento en la cantidad de asambleas realizadas, como así también la dinamización de órganos de base como los cuerpos de delegados y la comisión interna, todas cuestiones que apuntan a fortalecer mecanismos de democracia sindical; 2) la presencia de varias organizaciones militantes revolucionarias; 3) un importante nivel de movilización y presencia en la calle, ganando el espacio público vedado por la dictadura; 4) la sistemática represión policial y empresarial; y 5) la relación obrero-estudiantil. ${ }^{53}$

Respecto a este último punto, lo que rápidamente se puede identificar es el aspecto exterior y visible del asunto, por ejemplo el gran apoyo del 
movimiento estudiantil universitario durante el conflicto de 1971, ya sea con el fondo de huelga, actos y espectáculos. Y quizás también estos estudiantes, que venían movilizados de años previos, hayan sido un factor determinante a la hora de ayudar a los obreros disputar la calle durante el conflicto. De hecho, a partir de distintos informes policiales se puede comprobar que los detenidos luego de las movilizaciones son tanto obreros como estudiantes. ${ }^{54}$ Sin embargo, gran parte de lo que subyacía en esa relación obrero-estudiantil era resultado de las políticas de proletarización que varias organizaciones políticas llevaron adelante desde la mitad de la década de los años ' 60 .

Frente a los aspectos comunes con los procesos de radicalización obrera en otros lugares del país, lo singular de la experiencia de lucha en la empresa Petroquímica Sudamericana, y por ende de esta etapa del clasismo local, radica en cómo esta nueva camada militante logró vehiculizar los reclamos de los trabajadores: por medio de una comisión interna combativa articulada a una dirección gremial peronista muy permeable al activismo de base. Se llegó así al año 1971, cuando la fábrica se transformó en una olla a presión:

... desde hace seis meses los delegados gremiales han solicitado la construcción de un comedor dentro del establecimiento, pedido que no fue satisfecho pese a las promesas formuladas [...] la reparación de los baños, que se hallan en deficiente estado; la instalación de mayor cantidad de relojes de control de entrada y salida de los obreros, ya que existe uno para más de mil trabajadores y la construcción de bebederos [...] la empresa ha promovido inconvenientes para la actuación de los delegados de la comisión interna y muchos supervisores controlan el normal desenvolvimiento de las tareas haciendo mostración [sic] ostensible de armas de fuego. ${ }^{55}$

Estas demandas desataron a fines de febrero de ese año una serie de paros cortos que produjeron el despido de más de 300 obreros, decisión finalmente suspendida por una conciliación obligatoria. Sin embargo, en una asamblea la comisión interna dejó en claro que no daría el brazo a torcer hasta lograr "el fiel cumplimiento del convenio de trabajo". Y ello será el motivo de fondo de la larga huelga de aquel año, que significaría el primer gran conflicto obrero de la zona es aquella época, desde la huelga petrolera de Ensenada de 1968. Estas huelgas tienen varias coincidencias: fueron importantes conflictos que se prolongaron alrededor de dos meses, involucraron miles de obreros y terminaron con una gran cantidad de despedidos, entre ellos los militantes sindicales que iniciaron y sostuvieron el movimiento. La intransigencia patronal fue dura en ambos casos y no dejaron de estar atravesados por hechos 
de violencia de diverso tipo. Pero la gran diferencia es que logran expresar dos épocas distintas del conflicto laboral en la región.

\section{UN NUEVO CAMPO SINDICAL LOCAL}

Como respuesta a los procesos económicos y políticos desarrollados en la década de 1960, hacia principios de los '70 se conforma en la región platense un campo de fuerzas sindicales con características no vistas desde los años del primer peronismo: la hegemonía local sindical peronista, aún con importantes disputas internas, deberá enfrentar desde ese momento -y hasta 1976, año del golpe militar- una tendencia de izquierda que tendrá poder de organización, lucha y movilización en grandes empresas y fábricas de la región. Aunque hubo agrupamientos sindicales vinculados a la izquierda local con anterioridad, este sector recién se pudo realizar y tomar significancia a partir de estos años, de la mano de una nueva y heterogénea camada de jóvenes militantes obreros. La izquierda había dejado de ser un problema para el peronismo sindical platense desde la huelga ferroviaria de 1950/51. Posteriormente, con su reaparición pública luego de la caída de Perón, no pasó de ser una oposición localizada y débil, logrando tal vez algún cargo menor en un sindicato, o conducir alguno de ínfimo peso. Sin embargo, a lo largo de la década de 1960 parte de esta izquierda fue haciendo lugar a discursos y prácticas dirigidas a las condiciones de trabajo, que harán pie en Petroquímica Sudamericana, una de las grandes fábricas de la región que sufría frecuentemente procesos de racionalización productiva y persecución gremial, gracias a una camada -muy diversa políticamente- de militantes juveniles, varios de ellos estudiantes universitarios. Allí estalló el conflicto que llevaría a la izquierda platense a ser reconocida en la escena pública y política, y por lo tanto a definir un nuevo protagonista en el conflicto obrero de la zona, como contrincante que podía -al menos en los cálculos de ambos bandos- disputar la dirección de los conflictos y la politización del movimiento obrero. Aunque cabe aclarar, que esta oposición sindical no tuvo protagonismos permanentes ni una organización específica que la hegemonizara, cuestión que la diferencia de las experiencias sindicales alternativas al peronismo en otras zonas conflictivas del país por esos años, por ejemplo la de Córdoba.

Así, volviendo al debate planteado al principio del texto y a partir de este recorrido de historia local comparada, podrían plantearse como ideas centrales que a) las experiencias clasistas no fueron algo excepcional y localizado, b) sino que formaron parte de un conjunto de experiencias sindicales acotadas, con diversos grados de desarrollo y diversos resultados, y determinadas por transformaciones que se daban en realidades productivas y sociales específicas. Es decir la vinculación entre militancia laboral y 
radicalización política en la Argentina fue más que una experiencia obrera singular reducida a una sola zona del país, y esta cuestión puede ser planteada cuando se deja de concebir al clasismo como una categoría compuesta a partir de una sumatoria de ciertos rasgos, que estando presentes en cierto momento del desarrollo del fenómeno pasan a ser abstractamente constitutivos del mismo. Con ello, se corre el riesgo de descartar otras experiencias obreras por no surgir de las mismas condiciones o por tener resultados distintos al clasismo cordobés, pero que sin embargo forman del mismo fenómeno dentro del conjunto de las relaciones laborales del momento. Respecto a una tendencia o propensión de este tipo de fenómenos, es algo difícil de demostrar en términos cuantitativos, pero se podría afirmar que si existió una tendencia, fue la de un conjunto importante de organizaciones revolucionarias por justamente radicalizar el conflicto laboral de la época y conducirlo hacia una disputa por el poder político para alcanzar un cambio radical en la sociedad.

\section{NOTAS}

1 ARONSKIND, Ricardo. El país del desarrollo posible. En: Nueva Historia Argentina, Tomo IX. Buenos Aires: Sudamericana, 2003; BERROTARÁN, Patricia y POZZI, Pablo. Estudios inconformistas sobre la clase obrera Argentina, 1955-1989. Buenos Aires: Ediciones Letra Buena, 1994; JAMES, Daniel. Resistencia e integración. El peronismo y la clase trabajadora argentina (1946-1976). Buenos Aires: Sudamericana, 1990; PERALTA RAMOS, Mónica. La economía política argentina: poder y clases sociales (1930-2006). Buenos Aires: FCE, 2007; PORTANTIERO, Juan Carlos. Economía y política en la crisis argentina (1958-1973). En: ANSALDI, Waldo; MORENO, José (Comps.). Estado y sociedad en el pensamiento nacional. Antología conceptual para el análisis comparado. Buenos Aires: Cántaro, 1989; SCHNEIDER, Alejandro. Los compañeros. Trabajadores, izquierda y peronismo, 19551973. Buenos Aires: Editorial Imago Mundi, 2006; SCHVARZER, Jorge. La industria que supimos conseguir. Buenos Aires: Planeta, 1996; TORRE, Juan Carlos. Los sindicatos en el gobierno, 1973-1976. Buenos Aires: CEAL, 1983.

2 CAVAROZZI, Marcelo. Autoritarismo y democracia (1955-1983). Buenos Aires: CEAL, 1983; O’DONNELL, Guillermo. El Estado Burocrático Autoritario (1966-1973). Buenos Aires: Editorial de Belgrano, 1982; PORTANTIERO, op. cit.

3 CAVAROZZI, op. cit.; O’DONNELL, op. cit.; PERALTA RAMOS, op. cit.; PORTANTIERO, op. cit.

4 BONAVENA, Pablo; MAAÑON, Mariana; MORELLI, Gloria; NIEVAS, Flabián; PAIVA, Roberto; PASCUAL Martín. Orígenes y desarrollo de la guerra civil en la Argentina, 19661976. Buenos Aires: Eudeba, 1998.

5 BRENNAN, James; GORDILLO, Mónica. Córdoba rebelde: el Cordobazo, el clasismo y la movilización social. La Plata: De la Campana, 2008.

6 JAMES, op. cit.

$7 \mathrm{La}$ 'Resistencia' remite a un vasto e inorgánico movimiento popular que articuló un proceso obrero de resistencia a la ofensiva estatal y empresarial, con la lucha de las bases, activistas 
y algunos ex dirigentes peronistas por el regreso al poder de su líder, Juan Domingo Perón, exiliado en España, y que se desarrolló entre 1956 y 1960 aproximadamente.

8 CONINTES, eran las siglas del Plan de Conmoción Interna del Estado, y fue un estado de sitio permanente implantado por el presidente civil Frondizi, que entre fines de 1958 y mediados de 1961 significó la persecución y cárcel para cientos de militantes políticos opositores.

9 JAMES, op. cit.; TORRE, op. cit.

10 Se hicieron comunes en la época las 'huelgas generales', que decididas en altas esferas sindicales y con importantes grados de acatamiento, brindaron un importante poder de negociación a los dirigentes obreros frente al estado. La contracara de este proceso fue un aumento del control burocrático de los sindicatos, el acotamiento del disenso obrero y el crecimiento de los aparatos sindicales como generadores de consenso en las bases.

11 Aunque no existe un acuerdo preciso para definirlo, el Cordobazo fue un acontecimiento donde las masas populares de la ciudad de Córdoba, enfrentaron en las calle durante dos días a las autoridades gubernamentales luego de una trágica represión a la protesta obrera del día 29 de mayo de 1969. Se lo ha señalado como el primer gran golpe recibido por una dictadura que parecía bastante consolidada, y también como el puntapié inicial de un ciclo de protestas obreras de nuevo cuño.

$12 \mathrm{Si}$ bien la categoría clasista es aún motivo de debate, principalmente por su frecuente referencia a ciertos casos actuales de luchas obreras en Argentina, como categoría histórica trata de señalar a las experiencias -básicamente la de los trabajadores mecánicos cordobeses sindicalizados- que contuvieron algunas características disruptivas para la época: lucha por la democracia obrera contra las burocracias sindicales, posiciones definidamente antipatronales $y$ antigubernamentales, demandas que exceden reivindicaciones salariales y se concentran en los problemas del cotidiano laboral y las condiciones de trabajo, y el recurso a movilizaciones y prácticas combativas y hasta violentas al interior de las plantas industriales.

13 BRENNAN, James. El Cordobazo. Las guerras obreras en Córdoba. 1955-1976. Buenos Aires: Sudamericana, 1996.

14 BRENNAN, op.cit.; BRENNAN y GORDILLO, op. cit.; BRENNAN, James. El clasismo y los obreros. El contexto fabril del 'sindicalismo de liberación' en la industria automotriz cordobesa 1970-1975. Desarrollo Económico, № 125. Buenos Aires: IDES, 1992.

15 BRENNAN, El Cordobazo, op.cit., p. 451.

16 IÑIGO CARRERA, Nicolás. Acerca de los sesenta y los setenta. Anuario del IEHS, N ${ }^{\circ} 12$. Tandil: UNCentro, 1997.

17 BRENNAN, El Cordobazo, op.cit., p. 451.

18 IÑIGO CARRERA, Nicolás. La historia ¿Ciencia o Literatura? A propósito de la respuesta de James Brennan. Anuario del IEHS, Nº13. Tandil: UNCentro, 1998.

19 POZZI, Pablo. Excepcionalismo y clase obrera norteamericana. En: POZZI, Pablo; ELISALDE, Roberto; GONZÁLEZ CHIARAMONTE, Claudio; BILLOROU, María José. De Washington a Reagan: Trabajadores y conciencia de clase en los Estados Unidos. Buenos Aires: Cántaro, 1990.

20 SILVER, Beverly. Fuerzas del trabajo. Los movimientos obreros y la globalización desde 1870. Madrid: Akal, 2005.

21 JAMES, op. cit.; SCHNEIDER, op. cit.; TORRE, op. cit. 
22 Archivo de la organización Movimiento Revolucionario 17 de Octubre. Colección privada, folio 5, sin fecha, estimada fines de 1972.

23 Ibídem.

24 Los registros policiales que se utilizarán de aquí en más forman parte del archivo de inteligencia de la Dirección de Inteligencia de la Policía de Buenos Aires (DIPPBA). Allí se aloja variada documentación, tanto de origen policial (documentos de espionaje) como de procedencia obrera (volantes, publicaciones, etc.), que permiten acercarse a aspectos de la militancia sindical local por medio de un documento inéditos. En este caso se cita el expediente Asociación de Obreros y Empleados de Petroquímica Sudamericana. Mesa B, Carpeta 4, Legajo 6, folio 27, 18 de mayo de 1970.

25 Esta central sindical nacional surgió como alternativa a la CGT oficial, estableciendo frente a su postura negociadora, una actividad de oposición social y política a la dictadura, por lo que sirvió de referencia y articulación a diversas luchas sindicales del país, entre los años 1968 y 1970, aunque tuvo un peso dispar según regiones.

26 Sección "Elementos izquierdistas y agitadores gremiales de actuación en la Delegación Regional de la C.G.T. La Plata", del expediente policial Confederación General del Trabajo. Mesa B, Carpeta 2, Legajo 137, Tomo III, folios 782 a 785, 1 de abril de 1968. Obviamente, esto sólo recoge información de personas identificadas por el espionaje policial, no siendo entonces una muestra representativa de un posible universo militante regional.

27 Expediente Movimiento de Unidad y Coordinación Sindical. Mesa B, Carpeta 2, Legajo 174, folio 7, 17 de octubre de 1966.

28 Expediente Movimiento de Unidad y Coordinación Sindical. Mesa B, Carpeta 2, Legajo 174, folio 44, 10 de abril de 1967.

29 Ibídem.

30 LOBATO, Mirta. La vida en las fábricas. Trabajo, protesta y política en una comunidad obrera, Berisso (1904-1970). Buenos Aires: Prometeo Libros, 2004.

31 Expediente Frigorífico Armour. Mesa B, Carpeta 16, Legajo 11, Tomo II, folios 176 Y 177, 13 de enero de 1961. También se registra una importante presencia de los comunistas en las actividades desarrolladas durante el año 1962 junto a otras fuerzas políticas y sociales en el marco de la "Comisión Popular de Solidaridad con los Trabajadores de la Carne" en el marco de una larga huelga.

32 Expediente Sindicato de la Carne. Mesa B, Carpeta 16, legajo 11, Tomo II, folios 30 a 32 y 36 a 38,11 de marzo de 1971.

33 Este nombre deriva de su máximo líder, el trostskista argentino Nahuel Moreno, y de modo muy general representa un intento - cambiante dentro del devenir mismo de la historia argentina- por aggiornar las prácticas trotskistas a la política nacional, asumiendo ciertos procesos políticos-culturales para intervenir a partir de ellos: el caso paradigmático es la política de entrismo dentro del peronismo obrero. CASTILLO, Christian. El PRT-La Verdad entre los trabajadores de la carne de Berisso: La agrupación El Activista de la Carne y la Lista Gris (1967-1972). Cuestiones de Sociología, N 7. La Plata: Prometeo Libros, 2011.

34 Expediente Frigorífico Armour. Mesa B, Carpeta 16, Legajo 11, Tomo II, folio 74, 12 de septiembre de 1960.

35 Uno de los informantes de la policía que estuvo infiltrado en aquella reunión de unas 100 personas dejó su opinión sobre el papel del párroco plasmada en un informe: "Fue convicción del observador de tal mesa, que el Padre Ruberto, representa en esa zona un atajo para los 
argumentos arrolladores de la izquierda, y sólo con gran habilidad, en este caso invocando al peronismo, puede obtener en parte, que esa muchedumbre de trabajadores no sea absorbida totalmente por el Partido Comunista". Expediente Frigorífico Armour. Mesa B, Carpeta 16, Legajo 11, Tomo II, folio 347, 14 de septiembre de 1962.

36 Expediente Frigorífico Armour. Mesa B, Carpeta 16, Legajo 11, Tomo II, folio 399, 4 de noviembre de 1963.

37 Ante la muerte de tres operarios a principios de 1965, en un volante la lista Granate denunciaba el tema de esta manera: "A la patronal y sus médicos les decimos que está cerca la hora en que serán juzgados y ajusticiados por los tribunales obreros por delincuentes y explotadores y al gremio lo llamamos a organizar sus fuerzas, a imponer la aplicación del Plan de Lucha de la CGT, a que organice las secciones eligiendo delegados combativos para responder a las arbitrariedades y atropellos de la patronal". Expediente Frigorífico Armour. Mesa B, Carpeta 16, Legajo 11, Tomo II, folio 412, 3 de marzo de 1965.

38 Expediente Sindicato de la Carne. Mesa B, Carpeta 16, legajo 11, Tomo III, folio 560, 30 de abril de 1965).

39 BRETAL, Eleonora. La 'gran huelga' de Petroquímica de 1971 y una comparación con sus contemporáneas experiencias sindicales cordobesas. En: TORTTI, Cristina; PIOVANI, Juan (Comps.): V Jornadas de Sociología de la UNLP, $1^{\circ}$ Edición. La Plata: UNLP (CDROM), 2008.

40 BRETAL, op. cit., p. 115.

41 Expediente Asociación de Obreros y Empleados de Petroquímica Sudamericana. Mesa B, Carpeta 4, Legajo 6, folio 16, 25 de septiembre de 1970.

42 Ibídem, folio 8, sin fecha, estimada fines de 1965.

43 Ibídem, folio 41, 10 de marzo de 1969.

44 Ibídem, folio 46, 21 de junio de 1969.

45 El Día, 4 de julio de 1969. Es un tradicional periódico local platense.

46 Expediente Asociación de Obreros y Empleados de Petroquímica Sudamericana. Mesa B, Carpeta 4, Legajo 6, folio 48, 10 de mayo de 1970.

47 Esto puede verse en varios volantes del expediente Asociación de Obreros y Empleados de Petroquímica Sudamericana. Mesa B, Carpeta 4, Legajo 6, sitos en los folios 31, 32. 37, 38, 48, 49 y 55, siendo todos estos de 1970. En su anexo documental, Bretal cita una entrevista que señala uno de los problemas concretos que generaba esta disputa: "Claro, ese eran los del PCMLA. Éstos eran unos descolgados, porque recuerdo que un día pintaron 'Viva la CRC!' (Comisión de Resistencia Combativa) en el reloj de dónde íbamos a marcar, eso nos significó persecución, una serie de problemas iy ni siquiera sabíamos lo que era la CRC! Después tenían el siguiente criterio, como ellos eran clandestinos, nosotros no los conocíamos, pero le planteábamos que queríamos discutir esto, lo que habían hecho, pero no discutían porque eran clandestinos".

48 Expediente Asociación de Obreros y Empleados de Petroquímica Sudamericana. Mesa B, Carpeta 4, Legajo 6, folio 26, 18 de mayo de 1970).

49 La prensa se demostró muy interesada por este hecho: "Consultados sobre su anterior militancia en entidades gremiales, manifestó el señor Acosta: 'En realidad yo solamente integré la comisión reorganizadora de Petroquímica durante cuatro meses, mientras que mi compañero Spinatto desde 1964 actúa en SNIAFA”". El Día, 15 y 18 de septiembre de 1970. 
50 BRENNAN y GORDILLO, op. cit.; MIGNON, Carlos. Insubordinación obrera en Córdoba. Las ‘huelgas salvajes' de 1970-1971 en la industria metalmecánica y la experiencia del SITRAC clasista. ARCHIVOS de historia del movimiento obrero y la izquierda, $\mathrm{N}^{\circ} 4$. Buenos Aires: Programa de Historia del Movimiento Obrero y la Izquierda, 2014.

51 El Día, 13 de octubre de 1970.

52 El Día, 18 de noviembre de 1970.

53 BRENNAN, El Cordobazo, op. cit.; BRENNAN, El clasismo, op. cit. ; BRENNAN y GORDILLO, op. cit.; JAMES, op. cit.

54 Por ejemplo, de los 5 detenidos luego de la marcha del 28 de junio 1971, 3 son obreros y 2 estudiantes. El 27 de julio es detenido también un estudiante de ingeniería de 19 años, panfleteando en la fábrica volantes que llamaban a un plan de lucha, firmados por la "Comisión Obrera Clandestina". Expediente Asociación de Obreros y Empleados de Petroquímica Sudamericana. Mesa B, Carpeta 4, Legajo 6, folios 201 y 207, 28 de junio y 27 de julio de 1971 .

55 El Día, 14 de marzo de 1971.

Artigo recebido em setembro de 2015. Aceito em novembro de 2015. 